\title{
LA GUERRA EN LA PAZ: EL UNIFORME MILITAR Y LOS PREPARATIVOS ANTROPOLÓGICOS PARA LA GUERRA
}

\author{
WAR IN PEACE: MILITARY UNIFORMS AND ANTHROPOLOGICAL \\ PREPARATIONS FOR WAR
}

\author{
Lazar Koprinarov \\ Universidad Neofit Rilski de Blagoevgrad (Bulgaria)
}

Recibido: 20-05-2012

Aceptado: 26-06-2012

Resumen: En la primera parte del artículo se sostiene que entre la guerra y la paz no hay fronteras definidas y categóricas. Se desarrolla la idea de "preparación antropológica" de la guerra. En la segunda parte se explora el uniforme militar como un factor en la preparación antropológica de la guerra.

Palabras-clave: guerra, paz, uniforme militar, preparación antropológica de la guerra.

\begin{abstract}
The first part of the article argues that between war and peace there are no definite boundaries. It addresses the idea of "anthropological preparation" for the war. The second part analyzes the military uniform as a factor for this anthropological preparation.
\end{abstract}

Key-words: war, peace, military uniform, anthropological preparation for war.

"La vestimenta cambia nuestra visión del mundo y la visión del mundo hacia nosotros."

Virginia Woolf

\section{Las fronteras entre la guerra y la paz.}

Entre la guerra y la paz no existen fronteras categóricas. Incluso el título de, tal vez el libro más famoso sobre este tema - "La Guerra y la Paz" de León Tolstoi - no contiene en sí la línea divisoria, no discrimina y no enfrenta 
categóricamente la guerra y la paz ${ }^{1}$. Cuando Tolstoi escribe ésta novela, están de moda las novelas con fuertes oposiciones - antes de eso, Dostoievski recién había publicado "Crimen y castigo" y Turguenev "Padres e Hijos". Sin embargo, Tolstoi no describe la vida de sus personajes como una vida en mundos que no se relacionan y se oponen entre si. En la guerra, Natasha descubre el significado del amor y Pierre llega a verdades que hacen que su vida tenga sentido. Tolstoi cambia constantemente el enfoque de atención entre la vida pacífica y de batalla, pero no para enfrentarlas, sino para mostrar que en ambos "mundos" la gente y sus valores están expuestos a pruebas. El autor de "Guerra y Paz", muestra y dá sentido a las contínuas transiciones entre éstas dos formas de existencia humana.

Muy a menudo el inicio de la guerra es sorprendente. Como por accidente, por un disparo repentino, comenzó incluso la Primera Guerra Mundial - la guerra que con sus consecuencias determinó la naturaleza de todo el siglo $\mathrm{XX}$, transformándolo en el "siglo de la guerra". Sin embargo, las guerras nunca irrumpen como un cuerpo extraño en el mundo de la paz. De hecho, la paz las prepara, las "cria" dentro de sí, aunque pareciera que aparecen de repente como alcanzada por un proyectil inesperado que viene de otro planeta. La guerra cobra fuerza en condiciones de paz. La paz es, por lo general, un tiempo de doble transición - desde la existencia de la postguerra a la pre-guerra² ${ }^{2}$

[1] Sorprendentemente largo es el camino de Leon Tolstoi hasta llegar al título definitivo de la obra "Guerra y Paz". El autor publica los primeros capítulos de ésta novela bajo el nombre "1805". Los investigadores descubren en los manuscritos otra variante del título - "Todo es mejor cuando termina bien". A penas al final aparece el verdadero "nombre" de la novela. Tolstoi consideraba justo éste título, apenas el tercero en la historia de la novela, como el más acorde al sentido de la obra. El no desiste de él incluso cuando se publica la novela por primera vez a la par con la traducción al ruso del tratado, con el mismo nombre, de Pierre-Joseph Proudhon. Pero el título encierra en sí un enigma, el cual genera hasta el día de hoy discusiones en su interpretación. El problema surge del hecho que, en el idioma ruso la palabra “paz” tiene dos significados diferentes - „мир” (en ruso) significa la antípode de la guerra, pero también mundo. Al principio ambos significados tenían ortografía diferente: con “мир" describían la ausencia de guerra, mientras que con "мip" - mundo, universo. Más tarde, la diferencia gráfica desaparece y de ésta manera el significado de la palabra "paz" se divide. Por lo tanto, el título de Tolstoi "se puede entender no solo como conflicto de dos conceptos unilaterales (la guerra contra la paz), sino también como contraste entre un concepto mas general (la paz) y otro mas particular (la guerra como violación de las normas de la existencia humana y Divina)" - (cfr. Sukhij, 2007:78).

[2] La misma transición se puede encontrar en el mundo de la guerra. La vida del hombre en la guerra está marcada, tanto por las situaciones extremas de las batallas, como por las actitudes que se han formado en tiempos de paz. El investigador francés Frederic Rousseau llega a la misma conclusión tras analizar los resultados a los que es permitido que lleguen los historiadores al estudiar los testimonios personales de los soldados comunes de la Primera Guerra Mundial. Según él, el historiador debe interesarse, ante todo, en la actitud y los valores compartidos de los combatientes durante los combates y durante el descanso: "Aún en las trincheras y en el caos total, el combatiente actúa dependiendo de las relaciones sociales, las cuales ha logrado o no establecer con su entorno, con sus compañeros, con sus comandantes; actúa dependiendo de las relaciones que de alguna manera sostiene o acuerda con sus allegados ausentes que han quedado afuera

THÉMATA. Revista de Filosofía, Nº48 julio-diciembre (2013) pp.: 143-151

doi: 10.12795/themata.2013.i48.12 
A Clausewitz pertenece la fórmula que la guerra es la continuación de la política con medios militares. Pero en las últimas décadas en la historiografía militar, se impone un nuevo paradigma ${ }^{3}$, según el cual, la guerra se analiza desde la óptica del hombre. En esta perspectiva, la guerra es tratada, sobre todo, como "exceso cultural codificado de la violencia" (Novosadtko 2005: 124). Este exceso de violencia, típica de cualquier guerra, es el resultado de los preparativos llevados a cabo en condiciones de la vida pacífica. El potencial y la voluntad de grandes grupos de personas a participar en ese exceso de agresión se va acumulando mucho antes de su aparición. La paz y la guerra en este sentido no son opuestos absolutos. La preparación de la guerra comienza mucho antes de escucharse los primeros disparos - se inicia con los preparativos de desfrenar las inhibiciones morales de los grandes grupos de gente.

\section{Preparativos antropológicos de la guerra.}

Para entender en que consisten dichos preparativos "antropológicos" de la guerra, que son totalmente distintos a la preparación armamentista de las acciones bélicas, tenemos que descubrir la condición principal de cada guerra. Margaret Mead, quien define la guerra desde una perspectiva antropológica, la trata como un conflicto entre dos sociedades movilizadas, en el cual la privación de la vida de personas del bando opuesto no se sanciona, pero si eso ocurre entre las filas del mismo bando es tratado como crimen. Ella añade algo fundamental a esta definición de la guerra: los soldados de ambas comunidades deben estar preparados para matar y morir, subjetivamente convencidos de la legitimidad, el sentido y la idoneidad de sus actos (Mead, 1971: 236). Por lo tanto, condición sine qua non de la guerra es la condición de que un gran número de personas maten sin que se les trate de asesinos. Dicho de otra manera, la guerra se hace posible al dejar de lado las inhibiciones morales de los grandes grupos de personas, cuando se paraliza la resistencia de su conciencia.

Los investigadores sostienen que el género humano es el único en el reino animal, que ha superado la barrera biológica que impede convertir los "suyos" en objeto de destrucción. En los animales, la "paz" es una excepción más que una regla - por alimentos o una hembra están dispuestos a de-

del frente". - Según él, los testimonios personales de los soldados (cartas, memorias, etc.) son documentos que no pueden ser testimonios fidedignos para identificar los sentimientos del hombre en la guerra, ya que las emociones son transitorias, inestables o moderadas con miras a la censura militar o de acuerdo a la estrategia personal dependiendo de la persona a quien van dirigidas dichas cartas o memorias. Pero éstos relatos personales pueden "desenmascarar las normas sociales vigentes" (cfr. Rousseau 2011:178). O sea, los soldados en las trincheras se emocionan con lo que sucede a su alrededor, pero en el fondo de éstas emociones se hallan valores y actitudes que han sido llevadas a las tricheras desde el mundo pacífico.

[3] Tras el famoso libro de John Keegan (Keegan 1993), así como con el impacto de la antropología filosófica y cultural.

THÉMATA. Revista de Filosofía, No 48 julio-diciembre (2013) pp.: 143-151 doi: 10.12795/themata.2013.i48.12 
rramar sangre. Pero esto no es caza de semejantes, sino un "ajustar cuentas internos". El filósofo ruso Konstantin Krylov escribe con ocasión de esto: "Los lobos no cazan lobos. [...] El hombre es la única excepción a esta regla. [...] Esta capacidad de considerar absolutamente todo ente vivo como una presa potencial, no podría no llevar a la gente a que tengan el mismo punto de vista hacia ellos mismos, a referirse a ellos mismos como objetos." (2002 Krylov : 126). Buscando una explicación sobre la capacidad de la gente para destruir su propia especie, K. Krylov llama la atención sobre dos mecanismos para superar la barrera biológica de matar a su propia especie: el primero es el que los antiguos romanos llamaron furor y el otro - la "deshumanización" del Otro mediante la abstracción de sus cualidades humanas. El estado de furor, es decir la rabia, la locura, la furia, el frenesí, se acompaña por el abandono de varios mecanismos de defensa - el hombre está listo a matar y ser matado, el dolor ya ha dejado de doler, el instinto de auto preservación se debilita e incluso desaparece. Por lo general se logra y estimula a través de la embriaguez o del insulto desafiante ${ }^{4}$.

Carácter fundamental para lograr la deshumanización del Otro es lo que Hegel define como "pensamiento abstracto”. En su artículo “¿Quién piensa abstractamente" escrito en 1807, Hegel cita el siguiente ejemplo para ilustrar la especificidad del pensamiento abstracto: "Llevan un asesino al cadalso. Algunas mujeres tal vez indicaran que el es fuerte, guapo, un hombre interesante. Pero la gente que se halla reunida encontrará que esta observación es indignante. ¿Qué mal gusto encontrar aun asesino hermoso! [ ...]. El pensamiento abstracto es el siguiente: Que no veas en el asesino nada más que la abstracción que es asesino y aniquilar con esta abstracción lo humano en él." (Hegel, 1998: 383). Para la gente él es un asesino y nada más. El resto en él es invisible e indiferente desde el punto de vista moral. No hay un sentimiento más "asesino" que la indiferencia. Convertido en realidad no afectiva, el hombre desaparece - deja de existir como persona. La abstracción tomada como realidad, destruye la realidad.

Matar sin sentir culpa por el asesinato, significa, sobre todo, que se ha logrado tal estado de anímo, en el cual la individualidad se neutraliza - tanto la ajena como la propia. Estado en el cual el adversario pierde su rostro humano y se convierte en una abstracción. George Orwell, se pregunta durante la Segunda Guerra Mundial en "England, your England", cómo es posible matar sin ser un asesino. Al recrear sus experiencias durante el bombardeo sobre Londres, dice: "Mientras escribo éstas líneas, seres humanos altamente civilizados vuelan en el cielo y tratan de matarme. Ellos no sienten ninguna

[4] En éste contexto merece ser destacada una tésis artística de Tolstoi, contenida en "Guerra y La Paz". Según el escritor, la cercanía con la muerte genera libertad en los combatientes. Durante el enfrentamiento, donde se impone una pelea entre perros, los soldados comunes se liberan del dictado de la disciplina. Enfrentados con la muerte se convierten en libres. Su furor resulta fruto del peligro ante la muerte, que genera libertad, así como libertad de matar sin escrúpulos.

THÉMATA. Revista de Filosofía, No48 julio-diciembre (2013) pp.: 143-151

doi: 10.12795/themata.2013.i48.12 
hostilidad hacia mí como persona, ni yo hacia ellos, sólo están cumpliendo con su "deber" como se suele decir. No tengo duda de que la mayoría de ellos son de buen corazón, personas dóciles, que en su vida privada no hubiesen permitido siquiera la posibilidad de cometer un asesinato. Por otro lado, si uno de ellos logra aniquilarme con una bomba bien dirigida, no va a perturbar su buen sueño" (Orwell 1954:192). Orwell explica ésta "crueldad no intencionada" de la gente, en otras circunstancias bien intencionada, con la invalidacion de la responsabilidad personal, con su aniquilación. Como dice el escritor, éste, a primera vista bien intencionado hombre "sirve a su país que es capaz de exonerarlo de la culpa". Este proceso de transferencia de la responsabilidad está bien facilitado por el hecho de que las armas modernas crean grandes distancias entre el asesino y el asesinado. La víctima se vuelve invisible en el sentido literal y psicológico.

La disposición de matar metódicamente a la otra gente sin sentir remordimiento alguno, es producto de muchos factores - abrumado por el furor, bajo los efectos del cual la persona está a la vez dispuesta a matar y a morir; la manipulación ideológica, que garantiza la transferencia de responsabilidades; la técnica militar, que mata a gran distancia y hace que la víctima sea literalmente invisible y por lo tanto - invisible en sentido psicológico; el contagio colectivo de la agresión etc. Pero el pecado original, la base de la cual en última instancia, creció esta disposición de asesinar y agredir, es la abstracción de la invidualidad humana, que es una sustitución del hombre por el estereotipo del hombre. Como ha dicho acertadamente el ya citado K. Krylov, "para matar silenciosa y calmadamente al "Otro ", tienes que dejar de ver en él al hombre, o sea, es necesario que te abstengas de esta realidad" (Krylov, ibid). Por lo tanto, la preparación antropológica de la guerra se desarrolla como una actividad de elaboración de criterios por medio de los cuales se facilita la diferenciación y la distancia entre "suyos" y "extraños" y se alivia la aplicación del estereotipo de "extraños" en la medida en que ellos son percibidos como víctimas potenciales.

\section{El uniforme militar - la sombra de la guerra en la paz.}

En cualquier sociedad moderna el Cuartel militar es la institución que está especializada para llevar a cabo los preparativos, tanto militar como antropológicos de la guerra. El cuartel es el lugar donde las personas aprenden a manejar las armas de su tiempo. Pero también es el lugar donde se construyen las habilidades para reemplazar a la persona real con ciertos estereotipos del hombre, es decir, formar aquellos criterios y capacidades de abstracción sin los cuales no se podría matar a "Extraños" sin experimentar ciertos escrúpulos morales por ello.

El uniforme militar es una especie de representación visual del mundo de los cuarteles. En él se pueden descubrir muchos de los rasgos de la forma 
de vida militar, de la disciplina militar correspondiente, de los mecanismos de despersonalización. El hombre con uniforme militar es la transición entre el mundo de la paz y el mundo de la guerra, es el vínculo natural y evidente entre éstos dos mundos. El uniforme militar es el signo reconocible de la guerra en el mundo de la paz. Según la apreciación exacta del sociólogo búlgaro Iván Jadzhiyski, "el entrenamiento militar consiste en la creación de un hombre nuevo, quién al moverse sobre la línea entre la vida y la muerte (la cursiva es mía - LK) tiene que realizar tareas extraordinarias en condiciones extremas, por lo general en sentido opuesto a las líneas establecidas de su carácter civil y forma de vida" (Jadzhiyski 2002: 135). El uniforme militar, es la representacion visual de la vida entre la vida y la muerte, es la sombra de la guerra en el campo del aún mundo pacífico. A pesar que la guerra moderna - aquella cuyo inicio se dió con la Primera Guerra Mundial - es una guerra total, sin frente ni retaguardia, sin gran distancias entre civiles y uniformados, el uniforme militar sigue siendo la representación más significativa de la guerra en la paz. El uniforme militar es la encarnación visible de la abstracción que subyace en la capacidad de matar en masas sin escrúpulos morales. No todo el mundo con un uniforme militar, está listo para matar, pero el uniforme militar simboliza esta disponibilidad.

El hombre, al vestirse de cierta manera, "habla" de sí mismo. La vestimenta es su continuación particular, que le permite diseñarse, expresarse o simularse. Por medio de la vestimenta se crean más oportunidades para la expresión personal, para ampliar las capacidades del cuerpo humano, para la exposición de la individualidad, de la identidad sexual, política, religiosa, etc. Junto con ello, la vestimenta sirve también como una especie de código que facilita la comunicación. Al apoyar la auto-expresión, ayuda a la comunicación interpersonal.

Pero la vestimenta no es sólo una expresión de la persona. Es parte a la vez de aquellas herramientas con las cuales la sociedad produce y soporta varias clasificaciones sociales y estratificaciones (hombres - mujeres, jóvenes - viejos, clérigos y laicos, con autoridad y subordinados, militares y civiles, guardias y prisioneros, etc). La forma de vestir ha producido durante siglos la imagen de la estructura social de la sociedad. La vestimenta era el código semántico para descifrar el estatus de los diversos grupos sociales. Como se ha señalado por el historiador francés Le Goff (Le Goff 1999: 321-322) en la sociedad medieval la ropa juega un papel crucial en la categorización social. La vestimenta era una especie de "uniforme" del respectivo grupo social. La sociedad medieval hacia mayor énfasis en los diferentes accesorios de la vestimenta, especialmente en los sombreros y guantes, que eran algo así como los signos de las hombreras de los uniformes militares modernos. Ellos indicaban el rango de las personas que los llevaban. El uso de ropa inadecuada, vestimenta que no se correspondía con el estatus social, era tratado como un pecado 
o decadencia social. En la forma de vestir inapropiada descubrían la decadencia o el pecado del orgullo. Algo más, a finales del siglo XIII se emiten leyes especiales, que obligan a una cierta forma de vestir de acuerdo a la condición social y castigan a aquellos cuyas prendas de vestir se salen de los límites claramente establecidos por el simbolismo vestimentario de las estructuras de la sociedad. Estas leyes fueron motivadas por la preocupación de que la violación del código de vestimenta predispone y es una clara señal de rebelión contra el orden social establecido. La simplificación de la indumentaria se veía como una "manifestación no verbal a favor de un golpe de Estado político".

En su calidad de prolongación del cuerpo, como su peculiar prótesis cultural, la vestimenta está entre los lenguajes que permite al hombre "expresarse" y a la sociedad - a "organizarse" usando el lenguaje de la ropa. Cuando una persona elige su manera de vestir, el se "expresa" a sí mismo. Cuando la forma de vestir es impuesta, la ropa habla no acerca de él, sino de la institución que le ha impuesto ésta forma de vestir. Como es el caso con los uniformes militares.

Los uniformes militares aparecen en Francia a finales del siglo XVII. Desde un principio son un signo de pertenencia y subordinación a una estructura de poder determinada, así como forma de estandarizar ${ }^{5}$ el comportamiento de los soldados y oficiales. Como señala Jennifer Craik, en su libro "Uniforms Exposed: From Conformity to Transgression", el uniforme encarna la idea de control - del control no sólo sobre lo social sino también sobre el "yo" interno del hombre. Es la expresión visual de la idea acerca de las reglas y las jerarquías, de la disciplina, de la uniformidad y unidad, de la autoridad y obediencia, es decir, para cualidades en las que la individualidad del hombre uniformado pasa a un segundo plano.

J. Craik señala otra característica importante de los uniformes militares. Ella escribe: "El uso de los uniformes se rige por reglas, que son extremadamente detalladas y obligatorias en su cumplimiento. En realidad, son justamente ellas las que hacen del uniforme una pronunciación ya que su entendimiento y cumplimiento es sustancialmente más importante que los objetos mismos de la vestimenta o adornos que forman parte del uniforme" (Craik 2005: 4). De ésta manera, los uniformes militares no son simplemente una vestimenta, ellos son tal vestimenta, la cual juega un papel importante para la formación de las técnicas del cuerpo. El uniforme le cose al hombre quien la viste normas de comportamiento que "cambian" a esa persona. Además, pre-

[5] Gabriele Mentges destaca la relación entre la aparición de los uniformes militares y la industria de confección moderna. Desde los inicios de la producción de uniformes militares se implementan cuatro tallas como estándares en su elaboración. En dicha producción se imponen criterios tales como fabricacion serial, identificación mediante sencillos signos externos, funcionalidad, etc. Así se da el inicio a la industria de la confección. La producción de uniformes se halla en relación estrecha con la „produccion” de la Modernidad. (cfr. Mentges 2005:31).

THÉMATA. Revista de Filosofía, $\mathrm{N}^{\circ} 48$ julio-diciembre (2013) pp.: 143-151 doi: 10.12795/themata.2013.i48.12 
cisamente porque los uniformes implican normas estrictas de comportamiento, la individualidad del hombre vestido con el uniforme está bajo un control anónimo mucho más estricto. La socióloga búlgara Nina Nikolova lo detalla en su observación, que yo como uniformado siento mi cuerpo "como observado, como perseguido por miradas extrañas, como objeto pasivo de observación [...]. Hasta el punto que intento retener sus errores, yo lo veo como inactivo: para no cometer errores yo no debo actuar. Mi cuerpo está impedido por las miradas públicas."(Nikolova 2001: 77). Así, el cuerpo uniformado - cuerpo, perteneciente al poder disciplinario del cuartel militar - resulta ser un cuerpo "normalizado", o sea, cuerpo con una voluntad propia desconectada, disciplinado por normas abstractas.

Una de las funciones más importantes de los cuarteles y sus respectivos uniformes, como su representación visual, es la supresión de los hábitos civiles del hombre vestido de uniforme. El uniforme como que paraliza el cuerpo vivo y crea un cuerpo sumiso. Iván Jadzhiyski escribió en los años 40 del siglo pasado en su estudio "La Psicología de la disciplina militar": "Después de dos o tres días (una vez hayas ingresado al servicio militar) te sientes en la posición de una tercera persona (la primera persona es el jefatazo, la segunda - la identidad antigua y la tercera - tu nueva identidad), que sin intención alguna está siendo dirigida por una voz ajena y alta, así sea tu propia voz. Tu te tratas como a una persona ajena, haciéndola obedecer sin ningún tipo de razonamiento ni resistencia." (Jadzhiyski 2002: 146) El uniforme anónimiza tanto el cuerpo como en gran medida la espiritualidad del vestido con uniforme. Tal persona tiene un pie en el mundo pacífico y el otro - en el mundo de la guerra. Una persona que se mueve a lo largo de la línea entre la vida y la muerte. 


\section{Bibliografía}

Bauman 1989: Zygmunt Bauman, Modernity and the Holocaust, N.Y.: Cornell University Press.

Craik 2005: Jennifer Craik, Uniforms Exposed: From Conformity to Transgression, Oxford: Berg.

Hegel 1998: G. W. F. Hegel, Wer denkt abstract? - in: Gesammelte Werke, Band 5. Hamburg: Meiner.

Jadzhijski 2002: Iván Jadzhijski, Optimistichna teoría za nashia narod, t. II. Sofía: Iztok -Zapad (en bulgaro).

Keegan 1993: John Keegan, A History of Warfare, New York: Alfred A. Knopf.

Krylov 2002: Constantin Krylov, O filosofii armii. - en: "Otechestvennie zapiski”, 2002, № 8. (en ruso).

Le Goff 1999: Jacques Le Goff, La civilización del Occidente medieval, Barcelona: Paidos.

Mead 1971: Margaret Mead, Alternativen zum Krieg, in: Morton Fried/ Marvin Harris/Robert Murphy (Hg.), Der Krieg. Zur Anthropologie der Aggression und des bewaffneten Konflikts, Frankfurt a.M. 1971.

Mentges 2005: Gabriele Mentges, Die Angst vor der Uniformität, - in: Schönheit der Uniformität: Körper, Kleidung, Medien, Frankfurt/Main: Campus Verlag.

Nikolova 2001: Nina Nikolova, Politanatomiya na modernia chovek, Sofía: Crítica y Humanism.(en búlgaro).

Novosadtko 2005: Jutta Novosadtko, "Gewalt - Gesellschaft -Kultur": Ein Ersatz für "Krieg - Staat -Politik"?, in: "Zeithistorische Forschungen/Studies in Contemporary History", Online-Ausgabe, 2 (2005), H. 1, URL: <http:// www.zeithistorische-forschungen.de/16126041-Nowosadtko-1-2005>

Orwell 1954: George Orwell, England, your England and Other Essays, London: Secker \& Warburg, 1954.

Rousseau 2011: Frederic Rousseau, Saobstim opit i historia na boytsite prez 1914-1918. - en: "Problemi na sociologiata", 2011, edición especial (en búlgaro).

Sukhij 2007: Igor Sukhij, Ruskaya literatura XIX vek. - en: "Zvezda”, 2007, № 3 . 